\title{
DAMPAK DIGITALISASI TERHADAP INDUSTRI SKINCARE
}

\author{
Dila Komala Sari*, Arif Sugiono, Prasetya Nugeraha \\ Jurusan Ilmu Administrasi Bisnis, Fakultas Ilmu Sosial dan Politik, Universitas Lampung \\ * dilakomala.work@gmail.com
}

\begin{abstract}
This study aimed to determine how much influence e-service quality, e-advertisement, and celebrity endorser had on online purchasing decisions at Bening's Clinic skincare. The population in this study were Bening's Clinic consumers. The data were obtained from questionnaires that were filled out online using a Likert scale,. The sampling technique used was purposive sampling technique with a total sample size of 385 respondents from Bening's Clinic consumers. The data analysis of this research used descriptive data analysis and multiple linear regression analysis. The results of this study indicated that e-service quality partially did not had a significant effect on purchasing decisions, e-advertisement and celebrity endorsers partially have a significant effect on online purchasing decisions at Bening's Clinic skincare. In this study, trust and response were dominant factors that need to be maintained, because they determined Bening's Clinic's online skincare purchase decision as a beauty product.
\end{abstract}

Keywords: e-service quality, e-advertisement, celebrity endorser, purchase decision

\begin{abstract}
ABSTRAK
Penelitian ini bertujan untuk mengetahui seberapa besar pengaruh e-service quality, $e$ - advertisement, dan celebrity endorser terhadap keputusan pembelian secara online pada skincare Bening's Clinic. Populasi dalam penelitian ini adalah konsumen Bening's Clinic. Data tersebut diperoleh dari kuesioner yang diisi secara online dengan menggunakan skala likert. Teknik pengambilan sampel menggunakan teknik purposive sampling dengan jumlah sampel sebanyak 385 responden konsumen Bening's Clinic. Analisis data penelitian ini menggunakan analisis data deskriptif dan analisis regresi linear berganda. Hasil penelitian ini menunjukkan bahwa $e$-service quality secara parsial tidak berpengaruh signifikan terhadap keputusan pembelian, $e$-advertisement dan celebrity endorser secara parsial berpengaruh signifikan terhadap keputusan pembelian secara online pada skincare Bening's Clinic. Pada penelitian ini kepercayaan dan respon menjadi faktor dominan yang perlu dipertahankan, karena menentukan keputusan pembelian online skincare Bening's Clinic sebagai produk kecantikan.
\end{abstract}

Kata kunci: e-service quality, e-advertisement, celebrity endorser, keputusan pembelian 


\section{PENDAHULUAN}

Maraknya kegiatan transaksi jual beli online (e-commerce) dianggap lebih efektif dan efisien oleh masyarakat Indonesia. Hal ini dapat dilihat pada gambar 1 yang menunjukkan bahwa Indonesia merupakan negara yang mengalami pertumbuhan e-commerce paling pesat. E-commerce dapat dikatakan sebagai aktivitas transaksi bisnis secara online yang menggunakan jaringan internet sebagai media yang paling utama dalam menjalankan sebuah bisnis (Isyanahapsari \& Nurseto, 2018:3).

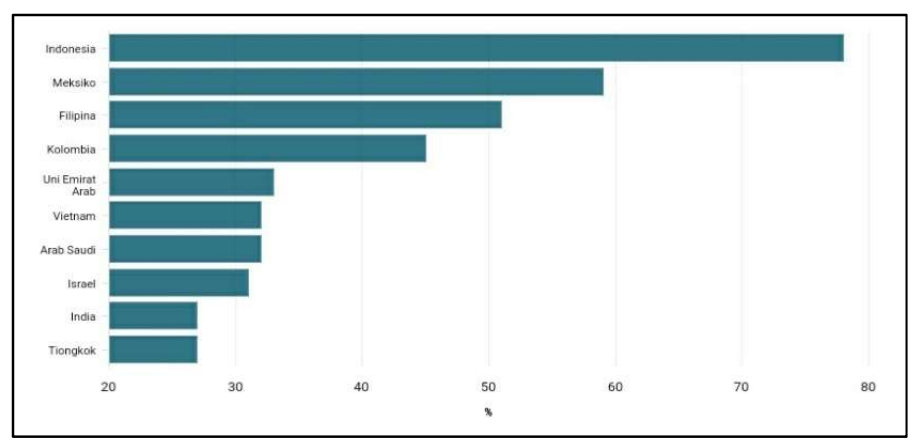

Gambar 1. Pertumbuhan E-commerce Paling Pesat (Databoks, 2019)

Pertumbuhan penggunaan e-commerce tersebut sejalan dengan berkembangnya bisnis klinik kecantikan di Indonesia yang menggunakan strategi penjualannya secara online, karena masyarakat Indonesia mulai memperhatikan penampilannya, khususnya wanita. Sehingga klinik kecantikan dapat menjadi bisnis yang menjanjikan di Indonesia. Setiap wanita berkeinginan untuk tampil dengan sempurna. Sudah bukan hal yang asing bagi wanita pada umumnya untuk memiliki fisik yang cantik dan awet muda, sehingga rela membelanjakan sebagian besar uang mereka untuk membeli suatu produk kecantikan (Arsitowati, 2017:84).

Seiring dengan meningkatnya kepercayaan diri perempuan dan peran perempuan di dalam berbagai bidang, kebutuhan akan produk skincare tumbuh semakin cepat. Hal ini berdampak baik bagi perusahaan yang bergerak di bidang kecantikan untuk terus berinovasi dalam mengembangkan produknya, sehingga menjadi produk yang lebih berkualitas dan memenangkan pasar persaingan.

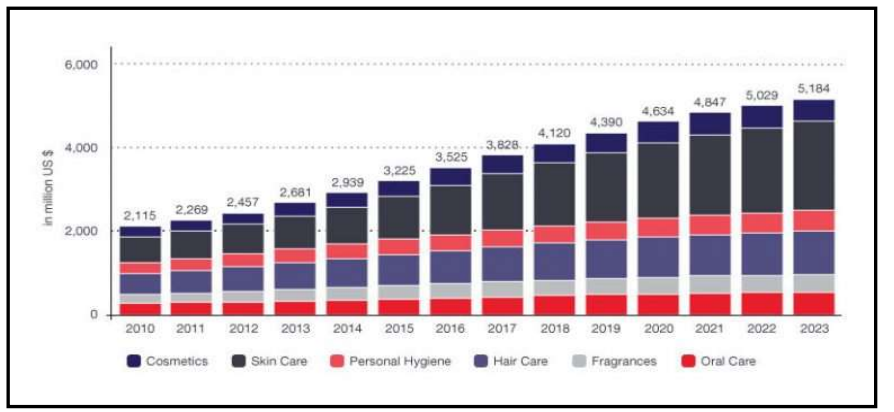

Gambar 2. Penjualan Kosmetik dan Ekspetasi Tahun Kedepan (pelakubisnis.com, 2020)

Meningkatnya kebutuhan produk skincare ditunjukkan pada grafik di gambar 2, yang merupakan grafik perkembangan penjualan kosmetik kecantikan yang terdiri dari cosmetics, 
skincare, personal hygiene, hair care, fragrance dan oral care sejak tahun 2010 hingga tahun 2020, dan ekspetasi perkiraan penjualan hingga tahun 2023 mendatang.

Dapat dilihat pada gambar 2, diketahui bahwa jumlah pertumbuhan penjualan produk skincare sejak tahun 2010 hingga 2020 sangat mendominasi dibandingkan produkproduk kosmetik lainnya. Hal ini terlihat dari grafik yang berwarna hitam merupakan grafik penjualan skincare. Dengan demikian, dapat diasumsikan bahwa produk skincare merupakan produk kecantikan yang paling banyak diminati oleh konsumen.

Salah satu klinik kecantikan di Indonesia yang menjual produk skincare adalah Bening's Clinic. Bening's Clinic merupakan klinik kecantikan yang mengalami pertumbuhan di setiap tahunnya. Hal ini dapat dibuktikan dari cabang-cabang Bening's Clinic yang tersebar di beberapa Ibukota di Indonesia, seperti Jambi, Palembang, Lampung, Pekan Baru, Medan dan Jakarta (Beritasatu.com, 2020). Di tahun 2020 ini, Bening's Clinic akan membuka cabang kembali di Kota Padang, Bandung, Yogyakarta, dan Surabaya (Wartakotalive.com, 2020).

Tidak hanya sukses mendirikan klinik kecantikan di kota-kota besar, Bening's Clinic juga sukses dalam penjualan produk-produk skincare. Hal tersebut dapat dibuktikan dari total penjualan produk skincare Bening's Clinic secara online melalui akun shopeenya tembus mencapai angka 10.000 produk yang terjual. Sedangkan untuk produk-produk Bening's Clinic lainnya, seperti produk perawatan tubuh, produk kosmetik wajah dan produk kesehatan hanya mencapai angka 2.000 produk yang terjual secara online (Shopee.co.id, 2021).

Berdasarkan data yang diperoleh melalui akun shopee Bening's Clinic tersebut, dapat diketahui bahwa produk-produk skincare Bening's Clinic merupakan produk best seller yang paling diminati oleh konsumen, dibandingkan dengan produk-produk kecantikan lainnya. Hal ini dikarenakan produk-produk skincare Bening's Clinic telah lulus uji BPOM, dan teruji klinis di laboratorium. Selain itu, produk skincare Bening's Clinic juga diawasi dokter serta apoteker yang terdaftar akreditasi, sehingga produk skincare tersebut dapat memberikan manfaat serta keamanan bagi konsumen Bening's Clinic (Wartakotalive.com, 2020).

Selain itu, pada tahun 2019, Bening's Clinic mendapatkan beberapa penghargaan yang disertifikasi oleh Kementrian Republik Indonesia, antara lain, Best Beauty Clinic 2019, Best Skincare 2019, Best Clinic with The Highest Number of Patients 2019, Best Beauty Clinic with The Most Online Product Sales 2019, dan Top Service Excellence Beauty Clinic 2019 (Instagram.com, 2021). Selanjutnya, menurut berita yang diunggah melalui akun instagram tersebut, Bening Clinic juga merupakan klinik kecantikan yang telah dinobatkan menjadi klinik yang memiliki banyak mesin Picosure Laser atau mesin laser termahal dan tercanggih nomor 1 di dunia.

Salah satu strategi yang digunakan oleh Bening's Clinic dalam menghadapi persaingan dengan klinik-klinik kecantikan lainnya adalah strategi penjualan dan pelayanan yang dilakukan secara online melalui aplikasi shopee, goshop dan instagram. Bening's Clinic juga mempromosikan produknya ke beberapa artis dan selebgram ternama di Indonesia. Hal ini bertujuan agar produknya dapat dikenal oleh masyarakat luas. Dalam menjalankan bisnis kecantikannya, Bening's Clinic melakukan pelayanan secara online kepada konsumen dengan cara membuka sesi konsultasi gratis pada media sosial instagram dan shopee. Strategi ini sukses dilakukan Bening's Clinic dalam mendekatkan produk kecantikannya kepada konsumen (Wartakotalive.com, 2020). 
Berdasarkan fenomena tersebut, untuk tetap mempertahankan performa yang dimiliki dan dapat bereksistensi pada dunia kecantikan, Bening's Clinic harus memahami dan memperhatikan perilaku konsumen agar konsumen tetap melakukan pembelian produk Bening's Clinic. Terdapat beberapa faktor yang harus diperhatikan dari segi ekonomi, budaya, politik dan teknologi (Mowen \& Minor, 2002 dalam Sangadji \& Sopiah (2013:14)).

Berkembangnya teknologi dapat memengaruhi gaya hidup seseorang dan memberikan pengaruh terhadap perilaku konsumen. Semakin pesatnya perkembangan teknologi, kebutuhan konsumen juga akan semakin meningkat. Sehingga faktor teknologi tersebut harus diperhatikan oleh Bening's Clinic dalam menerapkan strategi bisnis kecantikannya melalui penjualan dan pelayanan secara online, seperti e-service quality, eadvertisement, dan celebrity endorser untuk mempengaruhi keputusan pembelian konsumen.

\section{METODE PENELITIAN}

Penelitian ini merupakan jenis penelitian explanatory research dengan pendekatan kuantitatif. Populasi dalam penelitian ini adalah konsumen Bening's Clinic. Sampel dalam penelitian ini sebanyak 385 responden, yang didapat dengan menggunakan rumus Cochran, dengan tingkat toleransi kesalahan (margin of eror) sebesar 5\%. Penarikan sampel dalam penelitian ini menggunakan nonprobability sampling, dengan teknik sampling yang digunakan yaitu purposive sampling. Teknik pengambilan sampel dengan didasarkan ciriciri khusus yang sesuai dengan tujuan penelitian, sehingga diharapkan dapat menjawab permasalahan penelitian (Sugiyono, 2018). Penyebaran kuisioner penelitian ini dilakukan secara online melalui google form dan media yang digunakan melalui aplikasi instagram dan whatsapp.

\section{PEMBAHASAN}

Pengaruh Secara Parsial (Uji T)

Sesuai dengan hasil uji t statistik antara variabel service quality, e-advertisement dan celebrity endorser terhadap keputusan pembelian secara parsial, dapat dilihat pada tabel 1 di bawah ini:

Tabel 1. Hasil Uji T

\begin{tabular}{|c|c|c|c|}
\hline \multirow{2}{*}{ Variabel } & Strandardized Coefficient & \multirow{2}{*}{ T } & Sig. \\
\cline { 2 - 2 } & Beta & 5,585 & 0,000 \\
\hline Constant & & 1,206 & 0,229 \\
\hline E-Service Quality & 0,060 & 6.783 & 0,000 \\
\hline E-Advertisement & 0,341 & 5,231 & 0,000 \\
\hline Celebrity endorser & 0,271 &
\end{tabular}

Pengaruh E-Service Quality Terhadap Keputusan Pembelian

Besarnya pengaruh yang ditimbulkan sebesar $6 \%$, pengaruh tersebut bersifat positif, yang artinya semain tinggi e-service quality, maka akan semakin tinggi pula keputusan pembelian, sebaliknya semakin rendah e-service quality, maka akan semakin rendah pula keputusan pembelian. Berdasarkan analisis, nilai thitung $>$ tabel, yaitu 1,206 <1,996 dengan 
signifikansi 0,229 > 0,05. Artinya, secara parsial e-service quality tidak berpengaruh signifikan terhadap keputusan pembelian secara online skincare Bening's Clinic. Dengan demikian, maka $\mathrm{H} 1$ ditolak. Hasil penelitian ini bertentangan dengan penelitian yang dilakukan oleh Isyanahapsari \& Nurseto (2018), dan Pasha, et al. (2020) yang menyatakan bahwa $e$-service quality memiliki pengaruh yang positif dan signifikan terhadap keputusan pembelian. Hal ini dikarenakan menurut Lupiyoadi (2013:7), aktivitas ekonomi dalam perusahaan yang bergerak di bidang jasa memiliki hasil output produk bukan dalam bentuk fisik, umumnya dikonsumsi pada saat yang sama dengan waktu yang dihasilkan, dan memberi nilai tambah kepada konsumen seperti kesenangan, liburan, kesehatan atau pemecahan atas masalah yang di hadapi oleh konsumen.

Hal ini sejalan dengan pendapat Kotler dan Armstrong (2012:23) yang menyatakan bahwa jasa memiliki empat karakteristik yaitu tidak berwujud (intangibility), tidak terpisahkan (insheparibility), bervariasi dan tidak tahan lama. Dalam hal ini, karakteristik insheparibility (tidak terpisahkan) belum dapat mewakili pelayanan jasa secara online, karena jasa dijual terlebih dahulu, lalu diproduksi dan dikonsumsi pada waktu dan tempat yang bersamaan. Maka, dapat disimpulkan bahwa keputusan pembelian konsumen dalam aspek kualitas layanan secara online tidak didapatkannya pemecahan masalah terhadap apa yang dibutuhkan konsumen, melainkan hanya sekadar pembelian produk dan informasi produk, tetapi lain halnya jika konsumen melakukan pembelian secara offline, konsumen akan dapat berkonsultasi dengan dokter spesialis Bening's Clinic, sehingga mendapatkan pemecahan masalah atas keluhan yang dihadapi.

\section{Pengaruh E-Advertisement Terhadap Keputusan Pembelian}

Besarnya pengaruh yang ditimbulkan sebesar 34,1\%. Pengaruh tersebut bersifat positif, yang artinya semain tinggi e-advertisement, maka akan semakin tinggi pula keputusan pembelian, sebaliknya semakin rendah e-advertisement, maka akan semakin rendah pula keputusan pembelian. Berdasarkan analisis, nilai thitung $>t_{\text {tabel }}$ yaitu 6,873 $>1,996$ dengan signifikansi $0,000<0,05$. Artinya, secara parsial e-advertisement berpengaruh secara positif dan signifikan terhadap keputusan pembelian skincare Bening's Clinic. Dengan demikian, maka $\mathrm{H} 2$ diterima. Hasil penelitian ini sejalan dengan penelitian terdahulu Prasetyo, Yulianto \& Sunarti (2016) bahwa e-advertisement berpengaruh terhadap keputusan pembelian. Artinya, setelah melihat iklan online tersebut, konsumen akan lebih tertarik dan memiliki kepercayaan dalam memilih Bening's Clinic sebagai klinik kecantikan pilihan dibandingkan dengan klinik kecantikan lainnya yang tidak menayangkan produknya melalui iklan.

Berdasarkan uraian diatas dapat disimpulkan bahwa e-advertisement berpengaruh secara positif dan signifikan terhadap keputusan pembelian. Hal ini dikarenakan iklan ( $e-$ advertisement) memegang peran penting dalam memengaruhi calon konsumen untuk memutuskan melakukan pembelian suatu produk, karena konsumen cenderung akan mengamati iklan dari produk yang akan dibeli terlebih dahulu.

Iklan (e-advertisement) memberikan efek kepercayaan bagi calon konsumen khususnya untuk produk-produk membutuhkan kepercayaan dan kredibilitas yang tinggi seperti klinik kecantikan, untuk dapat meyakinkan konsumen akan kualitas, manfaat dan kinerja produknya. Melalui konten-konten dari iklan yang menarik, dan pemberian informasi, serta testimoni penggunaan produk yang dapat dipercaya, Bening's Clinic mampu 
menyampaikan pesan dalam sebuah iklan kepada konsumen, dan menciptakan sebuah perhatian, sehingga mampu memberikan pengaruh terhadap konsumen untuk memutuskan melakukan pembelian terhadap produk Bening's Clinic.

\section{Pengaruh Celebrity Endorser Terhadap Keputusan Pembelian}

Besarnya pengaruh yang ditimbulkan sebesar 27,1\%. Pengaruh tersebut bersifat positif, yang artinya semakin tinggi celebrity endorser, akan semakin tinggi pula keputusan pembelian. Sebaliknya, semakin rendah celebrity endorser, maka akan semakin rendah pula keputusan pembelian. Berdasarkan analisis, nilai thitung $>t_{\text {tabel }}$ yaitu 5,231 $>1,996$, dengan signifikansi $0,000<0,05$. Artinya, secara parsial celebrity endorser berpengaruh secara positif dan signifikan terhadap keputusan pembelian skincare Bening's Clinic. Dengan demikian maka H3 diterima.

Hasil penelitian ini mendukung penelitian yang dilakukan oleh Bramantya \& Jatra (2016) yang menemukan hasil bahwa celebrity endorser memiliki pengaruh positif dan signifikan terhadap keputusan pembelian. Selain itu, hasil penelitian ini sejalan dengan penelitian terdahulu Permatasari \& Yuniarinto (2018) yang menemukan hasil bahwa celebrity endorser berpengaruh signifikan terhadap keputusan pembelian, artinya bintang yang digunakan oleh Bening's Clinic mempunyai popularitas yang tinggi, sehingga ikut mempromosikan produk tersebut. Bintang iklan Bening's Clinic juga mempunyai pengetahuan tentang produk yang dipromosikan, sehingga memiliki daya tarik yang besar untuk mempengaruhi keputusan pembelian konsumen.

Berdasarkan uraian diatas, dapat disimpulkan bahwa celebrity endorser berpengaruh secara positif dan signifikan terhadap keputusan pembelian. Hal ini didasari oleh peran penting celebrity endorser yang dapat memengaruhi untuk melakukan pembelian produk skincare Bening's Clinic, dan meyakinkan calon konsumen bahwa promosi yang dilakukan secara objektif atau tidak melakukan manipulasi terkait produk yang diiklankan, melalui kemampuan kecakapan bintang iklan dalam menjelaskan informasi terkait produk, dan penggunaan produk.

Celebrity endorser yang dipilih Bening's Clinic merupakan artis-artis papan atas, seperti Roby Purba, Ria Ricis, Nikita Mirzani yang memiliki kredibilitas yang baik di mata calon konsumen mengenai pengetahuan tentang produk-produk skincare yang bagus dan bukan abal-abal. Hal ini menunjukkan semakin tinggi kredibilitas seorang celebrity endorser, maka semakin tinggi keputusan konsumen untuk melakukan pembelian produk, melalui kredibilitasnya ternyata mampu mempengaruhi seorang konsumen untuk melakukan keputusan pembelian produk.

\section{Pengaruh Secara Simultan (Uji F)}

Sesuai dengan hasil uji f statistik antara variabel service quality, e-advertisement dan celebrity endorser terhadap keputusan pembelian secara simultan, dapat dilihat pada tabel 2 di bawah ini.

Tabel 2. Hasil Uji F

\begin{tabular}{|c|l|c|c|c|c|c|}
\hline \multicolumn{2}{|c|}{ Model } & $\begin{array}{c}\text { Sum of } \\
\text { Squares }\end{array}$ & Df & $\begin{array}{c}\text { Mean } \\
\text { Square }\end{array}$ & F & Sig. \\
\hline \multirow{2}{*}{1} & Regression & 1570,637 & 3 & 523,546 & 59,256 & 0,000 \\
\cline { 2 - 8 } & Residual & 3366,273 & 381 & 8,835 & & \\
\hline
\end{tabular}




\begin{tabular}{|l|l|l|l|l|l|}
\hline & Total & 4936,910 & 384 & & \\
\hline a. Dependen Variable : Keputusan Pembelian & & \\
\hline \\
b. Predoctors : E-Service Quality, E-Advertisement, Celebrity endorser \\
\hline
\end{tabular}

Pengaruh E-Service Quality, E-Advertisement, dan Celebrity Endorser Terhadap Keputusan Pembelian

Berdasarkan hasil uji hipotesis (uji F) menunjukkan nilai $F_{\text {hitung }}>F_{\text {tabel yaitu 59,256 }>}$ 3,02, dan nilai signifikansi 0,000 $<0,05$. Berdasarkan hasil tersebut dapat diartikan bahwa secara simultan e-service quality, e-advertisement dan celebrity endorser berpengaruh positif dan signifikan terhadap keputusan pembelian produk skincare Bening's Clinic. Dengan demikian, $\mathrm{H} 4$ diterima.

Hasil uji koefisien determinasi (uji $\mathrm{R}^{2}$ ) menunjukkan bahwa angka $\mathrm{R}$ sebesar 0,564. Pada pedoman interpretasi, angka tersebut menunjukkan bahwa korelasi atau hubungan antara keputusan pembelian dengan ketiga variabel independen (e-service quality, eadvertisement, dan celebrity endorser) adalah sedang. Pada penelitian ini, nilai koefisien $\mathrm{R}^{2}$ dengan melihat nilai R Square sebesar 0,318 atau 31,8\%, hal ini menunjukkan bahwa adanya kontribusi variabel independen (e-service quality, e-advertisement, dan celebrity endorser). Hal tersebut menunjukkan bahwa persentase hubungan e-service quality, e-advertisement, dan celebrity endorser terhadap keputusan pembelian adalah rendah, sedangkan 68,2\% sisanya dijelaskan oleh faktor lain yang tidak diteliti dalam penelitian ini.

Berdasarkan uraian diatas dapat disimpulkan bahwa hubungan antara keputusan pembelian dengan ketiga variabel independen (e-service quality, e-advertisement, dan celebrity endorser) terhadap variabel dependen (keputusan pembelian) adalah rendah dan positif. Sehingga hipotesis penelitian ini diterima, yang berarti semakin baik e-service quality, eadvertisement, dan celebrity endorser yang dimiliki Bening's Clinic maka akan semakin tinggi tingkat keputusan pembelian konsumen.

\section{PENUTUP}

Berdasarkan hasil penelitian, secara parsial e-service quality tidak berpengaruh signifikan terhadap keputusan pembelian secara online pada skincare Bening's Clinic, dan $e$ advertisement dan celebrity endorser secara parsial berpengaruh signifikan terhadap keputusan pembelian secara online pada skincare Bening's Clinic. Namun demikian, secara simultan ketiga variabel berpengaruh signifikan terhadap keputusan pembelian secara online pada skincare Bening' Clinic. Pengaruh terbesar terletak pada variabel $e$-advertisement. Dengan demikian, pihak Bening's Clinic dapat mempertahankan aspek-aspek yang mendukung kualitas dari produk skincare yang diberikan dalam memenuhi kebutuhan konsumen, dan juga meningkatkan kualitas pelayanan secara online, seperti bekerja sama dengan pihak-pihak start up, seperti halodokter agar keluhan konsumen dapat langsung dijawab oleh dokter spesialisnya secara langsung. Selain itu, perlu pengelolaan manajemen waktu pengemasan produk, dan juga memilih jasa kurir yang tepat, agar produk dari Bening's Clinic sampai tepat waktu. Pengembangan penelitian lebih lanjut perlu dilakukan dengan mempertimbangkan penambahan variabel e-trust. Karena pada penelitian ini, kepercayaan memiliki nilai distribusi jawaban responden tertinggi pada variabel e- 
advertisement. Perlu juga dilakukan penelitian lebih lanjut untuk dapat mengukur dan mengembangkan variabel $e$-trust.

\section{DAFTAR PUSTAKA}

Armstrong, Gary \& Philip, Kotler. (2012). Dasar-dasar pemasaran, Jilid 1.(Alih Bahasa Alexander Sindoro Dan Benyamin Molan). Jakarta: Penerbit Prenhalindo.

Arsitowati, W. H. (2017). Kecantikan wanita Korea sebagai konsep kecantikan ideal dalam iklan new pond's white beauty: What our brand ambassadors are saying. Jurnal Humanika, 24(2), 84-97.

Beritasatu.com. (2020). Oky Pratama kian optimistis dengan benings clinic. Diakses dari [http://www.google.com/amp/s/www.beritasatu.com/amp/kesehatan/661681/oky-pratamakian-optimistis-dengan-benings-clinic].

Bramantya, Y. B., dan Jatra, M. (2016). Pengaruh celebrity endorser dan brand image terhadap keputusan pembelian yahama jupiter MX di Kota Denpasar. E-Jurnal Manajemen Unud, 5(3), 1745-1771.

Databoks. (2019). Indonesia jadi negara dengan pertumbuhan e-commerce tercepat di dunia. Diakses dari [http://databoks.katadata.co.id/datapublish/2019/04/25/indonesia-jadi-negara-denganpertumbuhan-e-commerce-tercepat-di-dunia].

Isyanahapsari, S., dan Nurseto, S. (2018). Pengaruh periklanan dan kualitas pelayanan terhadap keputusan pembelian secara online pada situs belanja online. Jurnal Administrasi Bisnis, 1-12.

Lupiyoadi, R. (2013). Manajemen pemasaran jasa berbasis komputer. Edisi 3. Jakarta: Salemba Empat.

Pasha, E. G., Wulandari, J., Adistya, D. (2020). Analisis e-trust, e-WOM dan e-service quality dalam keputusan pembelian online. Jurnal Perspektif Bisnis, 3(2), 63-75.

Pelakubisnis.com. (2020). Indonesia pasar potensial produk kosmetik. Diakses dari [http://pelakubisnis.com/2020/02/indonesia-pasar-potensial-produk-kosmetik].

Permatasari, P. B., \& Yuniarinto, A. (2018). Pengaruh celebrity endorser dan e-service quality terhadap keputusan pembelian dimediasi oleh brand image pada produk soflens pusbelshop. JIMFEB, 8(2).

Prasetyo, D. D., Yulianto, E., \& Sunarti. (2016). Pengaruh iklan secara online terhadap keputusan pembelian (Survei pada mahasiswa pengguna produk telkomsel internet 4G LTE). Jurnal Administrasi Bisnis , 41(1), 170-174.

Sangadji, E. M., \& Sopiah. (2013). Perilaku konsumen. Yogyakarta: Penerbit Andi.

Sugiyono.(2018). Metode penelitian. Bandung: Alfabeta.

Wartakotalive.com. (2020). Buka cabang baru di 4 kota benings skincare semakin manjakan konsumen untuk perawatan kulit tubuh. Diakses dari [http://www.google.co.id/amp/s/wartakota.tribunnews.com/amp/2020/04/14/buka-cabangbaru-di-4-kota-benings-skincare-semakin-manjakan-konsumen-untuk-perawatan-kulit-tubuh]. 